\section{AN EXAMINATION}

\section{CERTAIN RECENTLY REPORTED PHENOMENA IN CONNEXION WITH HYSTERO-EPILEPSY AND CEREBRAL ANÆSTHESIA.*}

By GEORGE SIGERSON, M.D., Ch.M., F.L.S., Member of the Royal Irish Academy, of the Scientific Society of Brussels, and of the Clinical and Anthropological Societies of Paris.

4. The Experimental Investigation.-The proceedings of a commission appointed by so distinguished a body as the Société de Biologie of Paris, to whom the methods and results were duly reported, must be assumed to have been guided by strict principles of scientific research. Sufficient evidence of care and forethought will, in fact, be found in its records to show explicitly what might well be taken for granted, that no ordinary precautions were omitted; whilst many unusual tests were adopted, in order to arrive at correct conclusions. It is possible, of course, to devise other examinations; but, if the means employed be sound and complete enough to justify the conclusions drawn, the Commission must be accorded all credit due for a duty well performed. The liability to errors of omission, to which all men are subject, is reduced to its least expression where the work done is submitted to the scrutiny of many experienced and independent observers not prepossessed in its favour, nor careless of testing its accuracy.

a. Safeguard's against Error.-Knowing the characteristics of the hysterical temperament, and remembering that they were appointed to decide upon alleged facts, the Commissioners were doubly vigilant. As a matter of course, they refrained from anything which should intimate to the patients what they thought likely or unlikely to occur; and, equally as a matter of ordinary duty, they took measures to prevent those upon whom they experimented from consciously or unconsciously misleading the judges. The eyes of the patients were closed before the metals or magnets were applied, in order that the presence of anæsthesia might be ascertained by severe tests; and they were maintained in that condition until a positive or a negative result was obtained. Certain circumstances, too, must be counted as favouring the testing character of the inquiry. If hysterical patients sometimes attempt to deceive, it should be noted that they occasionally aim to baffle the physician, and set his work at nought. They are as likely to deny what he may be supposed to want as to affirm its existence. One patient, for instance, refused to admit the return of post-metallic anæsthesia when it was obvious to all that she no longer felt any pain in the region examined. Some show themselves averse to being experimented upon ; and I can bear witness that more than once a trial had to be delayed or deferred because a patient had gone and hid herself. Next, it should be noticed that one of the patients was blind; so that, in her case, no hint of what was going on could be got by the organ of vision. Again, the presence of anæsthesia is most important from our present point of view, because, profound insensibility reigning over the region, it was impossible that the patient should discern by feeling where the metals were applied, much less distinguish between them by any accidental differences in form. Finally, hysteria, with all its artifices, can be eliminated from consideration, inasmuch as the application of metals has proved successful in cases from which it was absent.

b. Unexpected Results. - Even though it be shown that all due precautions have been observed, the critical mind may yet retain a lurking suspicion that some flaw exists still unperceived, some undetected error which the greatest care has not excluded. Psychical influence is such an elusive factor, and so exquisitely refined an agency, that one may not be entirely convinced that the safeguards mentioned have succeeded in excluding the operation of expectant attention. Now, the most convincing argument here is simply to show that the phenomena were so produced as to be utterly unexpected by the physicians and the patients. By this means, both suggestion and attention are put out of court. It becomes evidently impossible to allege "expectancy" as a factor when the result is a surprise.

If we should place a metal disc on a patient's arm whilst she is aware of what is done, and, by some hint or by some instinct, suspects what is anticipated, then indeed the result, if any positive result there be, might fairly be claimed as probably due to excited attention. But

* Concluded from page 145 of last number. discs of various metals are at hand, and the experimenter cannot foretell whether any of them, or, if any, which of them, may prove successful. One is applied and allowed to remain a certain time, during which the patient may be conceivably all attention; but the result is a disappointment. The same thing may happen as regards a second and a third metal, whilst the application of a fourth shall produce a visible change. The place in the series matters nothing; the first applied might be effective and all the others useless. It is sufficiently hard to imagine how expectancy could operate under such conditions; but it becomes impossible to conceive of it when we find that, once the effective metal is ascertained, you may change its place in the series and the same effect follows. But there is more coercive evidence to come. Several discs of different metals, say of zinc, copper, gold, and iron, are applied at the same time to the same patient, under the same conditions. Her eyes have been carefully closed before the experiment. The region to which the discs are applied is so completely insensible to touch as well as to pain, that she cannot know by her sensations whether anything is applied or not. The Commissioners can suggest nothing, because they know nothing in reference to the possible effect of any of the discs; it is to ascertain this that they make the trial. At different stages of the experiment, they apply the tests, and find that the anæsthesia persists around every metal, with one exception: at one spot around one of the discs, it may be any of the four, there is a recovery of feeling; for the patient winces when pricked there. An interval of some days is allowed to elapse and the experiment is repeated; another interval is followed by another examination; but the result remains constant. One metal, wherever it be placed, invariably succeeds, whilst the others inevitably fail. If the mind operate here, it can only be on condition that the cutaneous surface, when it lost all power of general sensation, acquired some new and wonderful perceptive faculty, which enables it to accurately discern the position of a particular metal which it cannot feel. Then its attention is bent upon that spot, and on no other, so that a strictly local effect shall be produced. If we could accept the statement that persons in a mesmeric condition have, with eyes closed, read books placed on various parts of their bodies, we might venture to suggest such an explanation, and say that certain powers of special sense had been temporarily generalised; but such an hypothesis would scarcely pass current here. These patients are rot in the mesmeric state, and make no pretension to the possession of such a faculty. On the other hand, when the effective metal has been discovered by the irreproachable means described, it can be tried in any way, and the efficacy of its application will assert itself whilst other metals fail. Thus, at the suggestion of Professor Vulpian, the patient Bar-, in whose case copper is effective, was left under the impression that it was reapplied; in reality, platinum was substituted for it, without her knowledge, and the result was negative, although the patient must have expected a positive effect. When, however, the platinum was removed and the copper used instead, the result was distinctly positive. What metal shall produce a change in any given instance, cannot be predicted. In the case of the blind patient Angèle, the anæesthesia was not affected by the contact of iron or copper, but was modified by that of zinc, and gave way to that of gold. On the other hand, the anæsthesia of the non-hysterical patient Rousille continued unaltered where the gold, copper, and zinc were applied, but was dissipated when the disc of iron was attached.

Hence it is obvious that the Commissioners could not lead the imagination of the patients, inasmuch as it was impossible for them to foreknow what metal should prove effective; and it is equally plain that the conditions of the trial were such as to eliminate the influence of expectancy in connection with any particular metal. Attention must have been excited by all the metals, if by any, when several were applied; yet only one becomes a factor. Confident expectation must have been at work when the patient (erroneously) believed that the metal to which she was sensitive had been applied, yet no change results.

Perhaps the most powerful argument, within its own limits, against the interference of a psychical cause is that supplied by the discovery of what is called the "phenomenon of transfer". It was manifestly quite beyond the capacity of the patients to form an idea of the possibility of such an occurrence. Dr. Burq had never thought of it; neither did any member of the Commission anticipate that such a thing would happen. There were no researches made in that direction with the object of testing a theory ; the observation of fact after fact made the inference simply imperative at last. The Commissioners tested the accuracy of Dr. Burq's statement that certain changes in circulation, feeling, temperature, and strength took place in the affected side. The dynamometer was employed, and it was ascertained that the grasping power of the affected hand gradually augmented. By way of comparison, the hand of the sound side was submitted to the same test, and its strength was found to diminish. The figures indicating these 
changes were noted down. Attention was simultaneously given to the condition of the special senses; and, in order that the state of the hearing should be accurately ascertained, Dr. Gellé was invited to conduct this portion of the examination. In doing so, he made use of his "interauricular tube", which enables the observer to distinguish the auditory acuteness of both ears comparatively. It was fortunate that he did not content himself with simply testing the changes which took place in the affected ear; for, if he had, the discovery of this curious transference might possibly not even yet have been remarked. When, however, he had noted down the figures indicating the changes observed, and came to compare the parallel columns, he perceived that in proportion as the ear of the anæsthetic side recovered its auditory acuteness, the ear of the opposite or "sound" side lost its hearing power. Now, mark the fact that up to this time it had been supposed that the application of metals was competent to effect a cure, or at least to completely free the hysterical patient from her anæsthesia for the time being. Hence it was certainly calculated to create some disappointment as well as surprise when Dr. Gelle, struck by the results of his comparative examination, remarked that the patient had not made a clear gain, as supposed, but that the disorder seemed to have only shifted its place. Dr. Landolt, the distinguished oculist, was at once asked to test whether this opinion held good as regards the eyes; and he quickly ascertained that the eye of the so-called "sound" side had lost that power of discriminating colours which it had possessed before the experiment, and which it was known the once affected eye had since regained.

Next, by various tests, the Commission made certain that the change extended to general sensation, and that the opposite half of the body, previously sensitive, had become anæsthetic; thus showing that, contrary to all antecedent belief, the patient had not made a clear recovery, but that there had simply been a transference of phenomena from one side to the other. This curious change must have taken place during previous experiments, and been overlooked, the attention of the physicians being confined to the dissipation of the anæsthesia from the affected side. Here, then, we have every proper guarantee against the interference of a physical cause. The experimenters never even remotely suspected the possibility of a phenomenon which yet must regularly have taken place whilst unobserved. The discovery of its occurrence was calculated to disappoint as well as to astonish, whilst the manner in which it was reached was the result of a happy chance, not a proposed research. The conjunction of such conditions is evidently incompatible with the operation of expectant attention.

Such a transference as that described, though most curious in itself, is not inconsistent-nay, it is even in harmony-with some long known clinical facts; and I would venture to suggest that, had the more familiar term " metastasis" been thought of and adopted, instead of the novel appellation employed, the account would have been received with much less hesitation. Under this designation, many strange phenomena of transference pass current without challenge.

c. Physical Agency.-Having shown that dissimilar causes may produce such a result as the hystero-epileptic paroxysm, our knowledge of this fact must not be forgotten. Hence I do not contend that it is impossible for a psychical agent to produce some at least of the other phenomena described. I await the evidence. It is sufficient for my present purpose to show that the interference of expectant attention does not vitiate the results ascribed to physical agencies. Another question is the mode in which these agents operate; and, although this is beside the main subject, there are certain points of interest connected with it which may claim attention. It is a duty to vindicate the veracity of new facts; but these become more acceptable when any rational explanation of their appearance can be suggested. That, on the application of certain metal discs to the surface, remarkable changes take place without the concurrence of a psychical cause, seems so unlikely, that the coercion of evidence only compels the mind to admit it with lingering reluctance. Perhaps a consideration of the following statement may render its acceptance more easy. At an early period of the investigation, Professor Charcot suggested that possibly the effect was due to some electric action determined by the application of a metal to the skin. When the facts came before the Société de Biologie, Dr. Onimus, whose researches on electro-therapeutics are well and favourably known, observed that the metals were not chemically pure; that, when applied to the skin, they became slightly oxidised; and that, under such conditions, the metallic disc became an electric element. The electro-capillary theory of Becquerel was also referred to. In order to put this question to the test, the co-operation of $\mathrm{M}$. Regnard was secured. His technical skill may be inferred from the fact that he was assistant to the eminent physiologist Professor Bert, and his ability from that of his recent appointment to the new Chair of Anatomy and Physiology in the Agronomic Institute. Making use of an extremely sensitive galvanometer, it was found that a feeble electrical current could be detected when one metal was applied, and a current of different strength with a different metal. The metals having been removed, the next question was whether similar feeble currents could by themselves produce results analogous to those produced by the discs; and, when the experiment was made, this supposition was proved to be correct. Without going into details, it may be mentioned that a suggested explanation of the action and inaction of different metals is supposed to be found in the different degrees of current-force occasioned by their application, and in the fact that currents of the same strength are not equally effective with patients of dissimilar idiosyncrasies. Thus the application of gold gives rise to a very feeble current, that of copper to one considerably stronger. In a patient sensitive to gold, when this metal is removed, a similar feeble current will produce a similar eftect, whilst a stronger current will not occasion any change. On the other hand, the patient sensitive to copper experiences no effect (in the absence of this metal) when a very feeble current is administered; but her anæsthesia gives way before a stronger current. This is sufficient, so far as the suggestion of a rational explanation is concerned; but a little more may be added. Patients sensitive to gold were found sensitive to currents measuring from 2 to $12 \mathrm{deg}$. of the galvanometer; those of the copper idiosyncrasy, to currents of from 30 to $40 \mathrm{deg}$. When the strength of the current was augmented, the patients in both cases experienced no effect until certain higher points were reached, when they again became sensitive.

There can be no doubt as to the fact that electrisation, without psychical interference, is sufficient to influence hysterical (and other) anæesthesia. Many years have elapsed since I)r. Ducherne (de Boulogne) demonstrated its power and remarked upon the variability of its effects upon patients of different idiosyncrasies. The return of feeling around a metal disc is heralded and accompanied by phenomena similar to those he observed on making use of the excitator wires (in localised faradisation); whilst the effect, circumscribed or generalised, and its occasionally transient duration, resemble the results obtained by the application of metals and magnets, and tend to support the suggested explanation.

Next, it should be added that the experiments with the magnet were made with equal care and precaution to what we have seen employed. There is, indeed, here a safeguard which may well replace that which we found in the simultaneous application of several metals. It is this : the magnet will not come into contact with the skin at all. The paticnt's eyes are closed before the experiments, in order that the presence of anæsthesia may be ascertained by pricking; then (the eyes being still kept closed) the magnet is approached and maintained within a short distance of the surface, whilst an occasional pricking is made to ascertain what change, if any, has taken place as regards sensation. Thus there is not even contact with the anæsthetic skin, and the patient has no imaginable means of knowing the position of the magnet (which has sometimes been applied to the back); nevertheless the zone of nascent sensibility makes its appearance opposite the poles. On the other hand, when the convex end of the horseshoe magnet has been brought near, no effect has ever been detected.

5. A Crucial Test.- If anything remained to be desired, after the very complete series of tests applied by the Commission, it has been supplied by the independent examination and experiments of foreign visitors, among whom may be mentioned Professors Westphal and Schiff. As it was my good fortune to assist recently at an investigation conducted by the latter eminent physiologist, which yielded unexpected results of the highest interest, that have not yet been published, a narration of the circumstances may be considered acceptable. Professoi Schiff entered upon his examination of the various phenomena related, fully impressed with the necessity of vigilance, admitting nothing as proved to his mind until the evidence had been carefully scrutinised. Having recognised that certain remarkable facts had been discovered, he proceeded to make some independent investigations in $\mathrm{La}$ Salpêtrière, for which Professor Charcot had accorded him all the facilities he desirepd. The most important of these was thus conducted. Before the patient $\mathrm{Bar}$ - was brought into the hall, certain preparations were made by Professor Schiff; and, in particular, a screen was placed across the table, so that it should be impossible for the patient to notice the slight movement of the fingers required to make a break contact. There were present Professor Schiff, M. Regnard, and myself. Nothing was said by the distinguished physiologist as to what he anticipated, or whether anything was expected; the experiments were conducted in almost complete silence, and the results left to speak for themselves. When the patient had taken her place in front of the table, M. Regnard closed her eyes, and demonstrated, by pricking, the presence of slight hemianæesthesia. Then the small solenoid was placed upon an anæsthetic finger, which passed through it; and a given space of time was 
allowed to elapse. Return of feeling had always hitherto taken place in a shorter space; but here there was none. Next, another few minutes were allowed to elapse, and recovery of sensation in the finger was detected, the patient withdrawing her hand when the finger was pricked. During the first period, the circuit was open; during the second, it was closed. The experiment was repeated, with identical results. As the screen was interposed between Professor Schiff's hand and the patient, the time of making or breaking contact could not in any case be known to her, nor even, I believe, to M. Regnard, who stood silently near, testing at intervals the state of sensibility present. Professor Schiff stood a little way apart, at the end of the table.

The succeeding experiment had the advantage of being entirely new, and of yielding results wholly unexpected by any of us. A large cylindrical bobbin (solenoid) was elevated on the table, so that one end should be opposite the patient's mouth, a space of about a foot intervening. The presence of right hemianæsthesia having been ascertained, her eyes were left open, and a roll of paper was placed between her mouth and the solenoid, so that, when she breathed through it as directed, her breath, going and coming, passed through the central cavity of the bobbin. After some minutes of silent waiting, she suddenly passed into a state of somniation; and, as she was then insensible, no test could avail. Fears were expressed that the experimentation would have to be abandoned, since it appeared to entail this disappointing result. However, I was able to point out that this result was not due to a cause inherent in the investigation. From my position at the other side of the table, I had observed the patient's gaze become steadfastly fixed on the solenoid cavity before her, to which the paper tube extended; and that, soon afterwards, quivering of the eyelids and som: niation supervened. Hence I suggested that she had lapsed into this condition because of having thus fixed her gaze; and that, if this were avoided, the experiment could proceed, when she should be aroused. [I mention this incident as a proof that the patient's mental energies were not so directed as to favour the result to come.] My suggestion, having been accepted, was found correct, when, the patient having been aroused and directed not to watch any particular spot, the experiment was resumed. After a considerable space of patient waiting, there was no change to be discerned in the anæsthetic region. Next, after another and a briefer lapse of time, it was ascertained that her right hand had become sensitive to pain. During the first period, Professor Schiff had prevented the current from passing; during the second, the circuit had been closed. Now comes the most remarkable result.

Having ascertained that sensation had returned in the right hand, arm, and right half of the head, M. Regnard proceeded, as usual, to prick the opposite side, which becomes anæsthetic, owing to the phenomena of transfer, already mentioned. To our surprise, the patient suddenly winced, exclaiming that she was hurt. It was then clearly ascertained that the left side was as free from anæsthesia and as sensitive as the right. Consequently, this time there had been no transfer, so far as general sensation was concerned. Next, the question of special sense was inquired into. Usually, as we know, the achromatopsia of the affected eye is simply shifted to the other visual organ; but here it was quickly demonstrated that the patient could distinguish colours equally well with both eyes.

In fact, the result of this experiment showed a clear gain to the organism, instead of a simple metastasis. The sensibility was tested in the hands, arms, neck, and head; and the only exception to complete (but not persistent) recovery was observed in the hyoidean region, which remained anæsthetic. If the question be put, why the phenomenon of transfer did not take place in this case, it may be replied that the only reason seems to be that the solenoid occupied a mesial position, and the air, entering through it and electrically affected by it, acted upon both sides of the system with equal power.

Professor Schiff, to whom I have recently submitted my account of the experiment, in order that he might judge of its accuracy, makes some highly interesting remarks in the course of his answer. Having confirmed the fidelity of my narration, and assented to its being published, he writes: "There was also another series of observations, at which probably you did not assist. I have seen that the efficacy of the solenoid is very well marked if it be put in communication with one pole $^{*}$ (positive or negative) whilst the other is isolated in an envelope of

Reference is here made to one of the results of the electrical experiments so care fully made by Dr. Romain Vigouroux and M. Regnard. In connection with this ex periment, and as helping to explain it, I may be permitted to mention a curious dis covery which first came under my observation two years ago, and which I have since repeatedly verified. Having had occasion to faradise the arm of a sensitive lady, she winced when I applied one rheophore to the (dried) surface ; whereupon, considering the act as due to her imagination, I pointed out that the application of the two rheophores was considered necessary to affect sensibility. She insisted, the two that she felt a slight prickling sensation; and, on listening attentively, I perceived that the usual crepitating sound was really, though but faintly, perceptible. Fre. glass or freely floating in the air. The efficacy of the respiration of air through the solenoid appeared probable to me, on account of some previous observations I had made in the case of an individual who suffered from time to time from a kind of neuralgia in the coccygean region. This neuralgia could with certainty be produced by placing his hand or arm in contact with the solenoid (with electric current), or even by respiration through it. That the hyoidean region, which is always more or less agitated by the movements of the larynx, occupies an exceptional position as regards its sensibility-that its cutaneous surface is less excitable - was first demonstrated to me by experiments on frogs tetanised by strychnine." Professor Schiff, it should be added (and the fact is characteristic of his cautious dealing with the subject) does not yet take it as absolutely proved that it is electricity that becomes active in the operations which awaken sensibility, until he can verify it by further experimentation on animals. "In the meantime," he writes, "it is well to certify facts which, at first glance, appear incredible."

This experiment, however, is conclusive, so far as the agency of expectant attention is concerned. It was impossible for any of us to betray, by word, sign, or expression, our anticipation of a consequence the advent of which none had conceived of. True, Professor Schift had reason to suppose that respiration through a solenoid might produce some effect, but not that it should produce this; for a renewal of pain in a neuralgic patient is not suggestive of the dissipation of hemianæsthesia. The experiment alluded to had taken place in another country, and was not mentioned until the close of this investigation. Hence it was here, as I have proved it to have been in other cases, totally impossible for the patient to derive from the action or expression of the observers a hint of what was likely to occur, or even to divine by any mystical perception of their thoughts. I can conceive of no way in which patients could acquire that insight into the future which should enable them to control the result, except by supposing that the application of metals and magnets endows them with the sibylline power of second sight, which to me seems improbable.

Concluding Remarks. - It cannot be denied that the main duty of the Commission has been well fulfilled. Directed to examine whether the allegations of Dr. Burq were correct or not, it has established that certain important results do follow the application of metals. What was first regarded as a chimerical fancy has been proved to be a fact capable of verification by the work of independent observers. More than this has been accomplished; for it has shown that similar results can be produced by the influence of the magnet and of electric currents. What I do not assert is, that the Commission has enumerated all possible causes; that was not in its charter to determine. Nor does the fact that other observers have added to its enumeration affect the conclusions legitimately drawn from its own experiments and not generalised. On the other hand, when it stated that the application of apparently inefficient objects (such as wood) has in one or two cases been followed by results, I am compelled to reiterate the opinion already arrived at; namely, that " psychical and physical agencies may produce identical results", and, consequently, that a demonstration of the efficiency of any one of these factors in a given case does not exclude the potential efficiency of the others. *

quently since, in the cases of children as well as of adults of both sexes, I have remarked that the application of one rheophore only suffices to give rise to fine crepiremarked that the application of one rheophore only suffices to give rise to fine crepitations, usually very faint. Perception of pain does not always accompany them; but
a slight prickling is generally felt when the rheophore is applied to very sensitive a slight prickling is generally felt when the rheophore is applied to very sensitive parts, such as the eyelid, the (dry) lips, or close under the ear, when the patient is
able to hear the crepitating sounds. The question next arose: "Is the place of the able to hear the crepitating sounds. The question next arose: "Is the place of the
other conductor supplied by the intervening air or solid substances?" Both are extremely bad conductors, for (whilst the large apparatus was at its full force) I could bring the two conductors into close proximity with the skin without the production of any feeling. Still, to avoid even improbable sources of error, I isolated the voltafaradaic apparatus, and then placed the patient in an adjoining room, twenty-seven feet from the instrument; connecting one end of a perfectly insulated wire with it, I closed the door of communication between the rooms, and repeated the experiment. The fine crepitating sounds were still heard as perceptibly as before, and the faint prickling as distinctly felt. Hence, I have been coerced to the conclusion that the crepitation in question is due to recomposition taking place at the cutaneous surface, the patient's tissue supplying the electrical elements necessary. 'That the action is on the parface, I tested by wetting the skin and rheophore, when no effect was noticed. the surface, I tested by wetting the skin and rheophore, when no effect was noticed.
Different states of the system and different idiosyncrasies seem to count for something Different states of the system and different idiosyncrasies seem to count for something
in the production of this phenomenon. In these experiments, I used Duchenne's great volta-faradaic apparatus, the current of the second helix, and the buttonrheophore.

Since the above was written,I find that Dr. Tuke has expressed a similar opinion (Fournal of Mental Scicnce, January 1879). He writes: "Justice, however, demands the admission that the influence of bone or of wood does not necessarily prove that metals do not exert an influence apart from the expectant attention aroused by their use, any more than the sleep or the purgation produced by a bread-pill proves that the jalap or the opium for which it was substituted possesses no virtue. It is possible to be misled by denying, as well as admitting, an alleged force." Dr. Tuke, also, candidly confesses that he failed to produce any result when he substituted for a metal didly confesses that he failed to produce any result when he substituted for a metal
plate a strong piece of card made to resemble it as closely as possible. He does not, plate a strong piece of card made to resemble it as closely as possible. He does not,
however, consider the experiment quite satisfactory, because the patient was not a 
With respect to the mechanism of the production of these phenomena by physical agency, I would explain it by the presence of a peripheral stimulus, which, being sufficient to affect the superficial nerve-fibres, would by this medium react upon the nerve-centres. "Can a local stimulus," it may be asked, "when applied to an anæsthetic region, have any influence beyond the immediate part?" To this I answer in the affirmative, for the following reason, amongst others. A patient came to me, the outer half of whose forearm, owing to a lesion of the ulnar nerve, was quite insensible. Desiring to test whether an experiment recorded by the Commission would be effective in such a case, I requested him to place a thimble on his little finger and to keep it there for half an hour. ${ }^{*}$ It was too large, however; and, to prevent it from slipping off the drooping and wasted hand, he had to maintain it in position with the other. But, when I had applied faradisation to the insensible part of the arm, he was surprised to find that the thimble no longer slipped off. The finger had increased sufficiently in size to fill it ; and this, of course, was due to an influx of blood, determined by a peripheral stimulus. $\dagger$ Again, in a case recorded by Dr. Duchenne (de Boulogne), where a patient was affected with intense anæsthesia of the left side, the faradic stimulus, though unfelt, wherever applied in that region, was followed by a sensation of dizziness, vomiting, and pain in the left side of the thorax, under the breast. On the right, or sound side, the local stimulus was normally perceived, and no such remote effects followed. Hence a peripheral stimulus, when applied to an anæsthetic region, is capable of reacting on the nerve-centres; and, judging from the last mentioned case, the presence of anæsthesia may even favour such an effect, by diminishing resistance or removing interfering forces.

When the efficacy of a metal-application was spoken of as due to some inexplicable "virtue" inherent in the object, it was natural that the mind should resent such a notion, and appeal to psychical action in preference. But the case assumes another aspect when we find that, on the application of metals, electric currents are generated; and when it is next demonstrated that, in the absence of the metals, these currents are sufficient to produce the same phenomena, there can be little hesitation in declaring that a satisfactory explanation is before us. On the other hand, there may be efficient stimuli other than electrical; and nothing justifies us in excluding from this category the irritation of a sinapism, for instance, or that caused by a ligature drawn so tight as to produce odema of the member. The actual cautery also might be equally effective. Before rejecting the possibility of a physical agency in cases where apparently inefficient objects are applied, it would be well to investigate whether some unnoticed cause has not been at work to disturb the electrical condition of the part. The researches of Du Bois-Reymond, it should be remembered, show that thermo-electric currents may be produced by inequalities of temperature not generally suspected of possessing such an influence, and that other readily overlooked causes may give rise to electro-motive action. The propriety of such an investigation becomes obvious when we find, by the experiments of M. Regnard, that comparatively feeble electric currents are sufficient to determine the production of the phenomena we have just reviewed.

I conclude in the memorable words of Claude Bernard: "The physiology of the nervous system is yet but very little advanced. If its instructions were to be waited for by pathology, the latter would be new comer in the hospital. On the other hand, I can certify that, judging by her ex-
pressions afterwards, she would scarcely have borne the experimentation so patiently pressions afterwards, she would scarcely have

* No recovery of sensation in the finger was experienced at the time, neither was its occurrence considered probable.

t It is suggestive that an effect should be produced where the sensations of touch, pain, tickling, and temperature are abolished, as they were in this case. The fact tends to corroborate Dittmar's opinion that there are special fibres, answering to electrical [mechanical and chemical] stimuli by reflex action through the vasomotor electrical [mechanical and chemical] stimuli by refex action through the vasomotor centres. Dr. Duchenne (de Boulogne) accounted for the active hyperæmia, observed
after faradisation, by supposing the existence of vaso-dilators. It is generally stated that Claude Bernard, who was chiefly responsible for the hypothesis of active dilatation, afterwards abandoned it; and this is true to a certain extent, but it should be added that he resumed its advocacy, and upheld it for some years previously to his decease, as I had many opportunities of knowing. Here I may refer to the statements of Dr. Bennett (Brain, vol. i, p. 335), that he has never seen the punctures which had been made in an anæsthetic region bleed on the return of sensibility; and that "the nature of the wound inflicted by the needle seems alone to determine if blood shall follow, and this whether the skin be anæsthetic or not. This may serve to explain the circulatory changes supposed to be produced by the metals." It does not, however, explain the elevation of temperature. But, in fact, nothing more quickly attracts the attention of medical visitors at La Salpetrière, than the sight of blood oozing out pin-pricks, on the return of sensibility, where previously there was little or nong out of pin-pricks, on the return

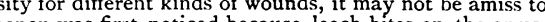
æamic phenomenon was first noticed because leech-bites on the anæsthetic side were found to yield but very little blood, whilst on the other side it flowed as usual. Professor Schiff's production of analgesia by the rapid withdrawal of blood should not be forgotten. Activity of capillary circulation, recovery of sensibility, and increase of temperature and of strength, seem to me to be very closely correlated. exposed to the danger of allowing important phenomena to escape. It is better that it should not wait, but rather continue to register facts, which are as so many problems, the solution of which must afterwards be sought out by physiology."

\section{T W O CASE OF H Y T E R I A.*}

By JOHN S. BRISTOWE, M.D., F.R.C.P., Senior Physician and Lecturer on Medicine at St. Thomas's Hospital.

CASE II. Hysterical Catalepsy: Mania: Double Consciousness, etc. -A healthy-looking, interesting, and accomplished girl was, without any obvious reason, attacked, in September 1873 , with pains in her chest-walls simulating those of intercostal rheumatism. They were supposed to be hysterical, and had subsided at the end of a week. But after a couple of days, again without apparent cause, she passed almost suddenly into a curious cataleptiform condition. Her muscles were perfectly rigid; her arms and legs and head and neck being extended so that she could be carried or lifted like a statue from one place to another; but her hands were firmly closed, and her feet similarly affected, so that the toes were flexed into the soles of her feet. The joints generally were so firmly fixed that no force that her medical attendant, Dr. Simpson, of the Old Kent Road, felt justified in employing, availed to move them. The only exceptions were the shoulderjoints and those of the head and neck. The arms, in fact, could be moved readily at the shoulders, and remained for an indefinite period in any position in which they were placed. The movements of the head and neck I will describe presently. She appeared to be entirely devoid of feeling, perfectly deaf, and her eyes were fixed, but she was not wholly insensible; for, although she took no notice of anything, or of anyone else, she always showed signs of pleasure, and moved her head from side to side, when Dr. Simpson came in the line of her vision. Yet she took no notice even of him when his image fell on the lateral parts of her retinæ. Her teeth were clenched, and she did not attempt to speak or to take food. But Dr. Simpson soon found that, on passing his finger backwards between her teeth and cheek, and then inserting the tip behind the teeth between the upper and lower jaws, the spasm of the jaws almost immediately yielded, and he was able to administer spoonfuls of milk. But there was still some difficulty in swallowing, and it was often returned, in part by the nose. He had to feed her four times a day. At the end of about a month, she recovered almost suddenly; and, when her hands and feet opened, the fingers and toes were found to have made deep depressions in the palms and soles respectively.

In December, her friends determined to take her to Brighton for the benefit of her health. Before she left, Dr. Simpson paid her a complimentary visit; and immediately after this she observed to her parents that, if she were taken ill there, she would have only Dr. Simpson to attend her. She left home on the Thursday, and on the following Monday morning a telegram reached Dr. Simpson requesting him to come down to her at once. He arrived at Brighton in the evening, and found her again cataleptic, and very nearly in the same condition as that from which she had recovered two or three weeks previously. Dr. Simpson then learnt the following facts about her, some of which were important, and others at any rate strange. It appeared, that about I I o'clock that morning she began to experience a sense of numbness and rigidity; and, being quite sensible at the time, she requested that Dr. Simpson should be at once sent for. Her parents went into another room, discussed the question, and decided not to telegraph (at any rate at once), but to tell her that they had telegraphed. They returned to the room and told her that they had sent her message. But she at once taxed them with their deceit; and the result was, that the telegram was sent off. At 12 o'clock, she said to her parents, "The telegram has reached Dr. Simpson's house, but he is not at home, and will not reach home until two." At two, she observed, "He has now got the message, but he is hesitating whether he shall come or not." Later on in the day, she said, "Now he has started," and about an hour or so afterwards she called out that his train was being delayed at Horsham, and that it would arrive at Brighton half an hour late. Now, all these assertions of hers were, Dr. Simpson asserts, absolutely true. He was out at twelve, when the telegram arrived; he did not reach home until two; and then he had to go to the London Hospital and get a locum tenens before it was certain that he could go to Brighton that day. His train, which she had timed accurately, was delayed half an hour at Horsham, and arrived at Brighton half an hour late. Her condition, as above remarked, was now, as nearly as possible, what it had been

* Concluded from p. 146 of last number. 